\title{
A metallurgical investigation on a failed superheater tube used in a thermal biomass power plant
}

DOI:10.36909/jer.14741

Jutaporn Chaichalerm*, Chaiyawat Peeratatsuwan**, Thee Chowwanonthapunya***

*Cortech Integrity and Expertise Co.,Ltd, Bangkok,10230, Thailand.

**Faculty of Engineering and Architecture, Rajamangala University of Technology Isan, Nakhonratchasima 30000, Thailand.

***Faculty of International Maritime Studies, Kasetsart University, Sriracha, Chonburi 20230, Thailand.

***Corresponding Author: thee.c@ku.th

\begin{abstract}
This article described the investigation of the failed superheater tube made of SA210 Grade C used in a biomass power plant. Visual inspection, microstructural examination, chemical analysis and hardness measurement were employed to analyze the causes of the superheater tube failure. Results from the investigation showed that the major cause of this failure was mainly related to the long-term overheating, resulting in the occurrence of the excessive thermal oxidation and graphitization. The excessive thermal degradation accelerated the reduction of the wall tube and promoted the build-up of the stress acting on the tube. Graphitization degraded the microstructure of the tube, reducing the mechanical performance of the tube. The combined effects from the severe thermal oxidation and graphitization attributed to the premature failure of the tube. It is therefore advised to use the correct material, SA213 T22, in the failed section. Material specification examination for superheater regions prior to tube installations should be performed to avoid the use of the inappropriate material. The temperature monitoring and mapping in this section were also suggested.
\end{abstract}


Key words: Boiler; Failure; Graphitization; Superheater tube

\section{INTRODUCTION}

In typical power plants, boilers are the major equipment used to produce the superheat steam by the combustion of obtainable fuels (Movahedi-Rad et al 2015, Peeratatsuwan and Chowwanonthapunya,2020). In the purpose of the environmental pollution reduction, the thermal biomass power boiler is considered as a considerable choice for electricity production (Jenkins,1989, Mckendry,2020). In addition, this kind of energy accounts for nearly $10 \%$ of the renewable energy for the electricity used around the world (Mckendry,2002). Technically, superheater tubes in the boiler are essential parts of the power boiler (Bahrami et al, 2019 , Pramanick et al 2017). They are normally placed in the hottest zone of boilers and used to carry the superheat steam which possesses the highest pressure and temperature. At the same time, these tubes have to be exposed to very high temperature produced by the burning of a variety of biomass-based fuels (Fryda et al , 2010). Usually, using these tubes beyond design limits for a prolonged period of time can bring about "long-term overheating", which subsequently resulted in the microstructural degradation of the superheater tubes. For examples, carbon steel tubes can be subjected to "spheroidization" to which lamellar iron carbides decompose into spheroidized iron carbides (Chatterjee,2012, Liu et al , 2017). Furthermore, these tubes can also be susceptible to "graphitization" where iron carbides dissociate to form ferrite matrix and nodular graphite (Perez , 2011). Both microstructural changes negatively affect the mechanical properties. Aside from the microstructural degeneration, long-term overheating can promote the transformation of steel surface to oxide layers, known as "thermal oxidation". Generally, thermal oxidation causes the wall thickness loss of the boiler tube. Such degradation mechanisms often lead to the premature failure of boiler tubes due to stress rupture (Saha et al, 2015, Ahmad et al , 2012). Industrially, the failure of the superheater tubes is the significant cause of the unplanned outage of that power plant, resulting in the substantial financial loss in 
different industrial sections [Saha and Roy, 2017]. Indeed, the failure degradation mechanisms of the superheater tubes are

complicated and so far, there has been little work conducted pertaining to the failed superheater tubes, especially in the degradation microstructural analysis. Hence, it should be of great importance to perform the metallurgical failure investigation on the failed superheater tube, which is imperative for understanding and evaluating the microstructural degradation evolution of the steel tube used in the actual environment of the biomass power plant and related environments.

In this paper, the systematic investigation was conducted on a failed superheater tube in a biomass fired thermal power plant. Visual inspection, metallographic examination and chemical composition analysis were conducted on the failed tube. Hardness measurement in undamaged and damaged areas was also carried out and analyzed to ascertain the probable cause of this failure. Besides, the failure mechanisms of this superheater tube were analyzed and discussed.

\section{EXPERIMENTAL PROCEDURE}

This analysis was carried out on the failed secondary superheater tube in a biomass-based power plant. A piece of the damaged tube was obtained for carrying out the failure investigation. In original condition, this tube had an outside dimeter of $33.5 \mathrm{~mm}$ and the wall thickness of 4.33 $\mathrm{mm}$. The design temperature of the operation for this failed tube was $540{ }^{\circ} \mathrm{C}$ with the operation pressure of $130 \mathrm{~kg} / \mathrm{cm}^{2}$. The material of this tube was reported to be SA-213 T22 alloy steel, the important alloying elements of which are chromium and molybdenum (Xiaowei,2014, Chowwanonthapunya and Wiriyanon,2015). This failed tube had been in service for 5 years. To analyse the failure of the obtained tube, visual examination of the tube was performed by naked eyes and a moveable enlarging lens. Microstructure examination was carried out using an optical microscope and a scanning electron microscope (SEM) to obtain more details of this failure. To perform the microstructural investigation, mounted samples were prepared from the 
damaged area of the obtained tube. They were ground on $\mathrm{SiC}$ paper down to 1,000 grade emery paper and followed by polishing them with a diamond polishing paste of $1 \mu \mathrm{m}$. This preparation is for as-polished samples. As-etched samples were prepared by etching polished samples with $2 \%$ nital solution. Both sets of samples were then investigated by optical microscope and scanning electron microscope. The phase analysis of the failed tube was conducted by scanning electron microscope equipped with an energy dispersive spectrometer (EDS). Hardness measurement was conducted on the failed part of the superheater tube to observe the hardness variation by comparing with that of the undamaged part. An emission spectrometer was employed to check the chemical composition of the damaged superheater tube.

\section{RESULTS AND DISSCUSSION}

\section{Visual Examination}
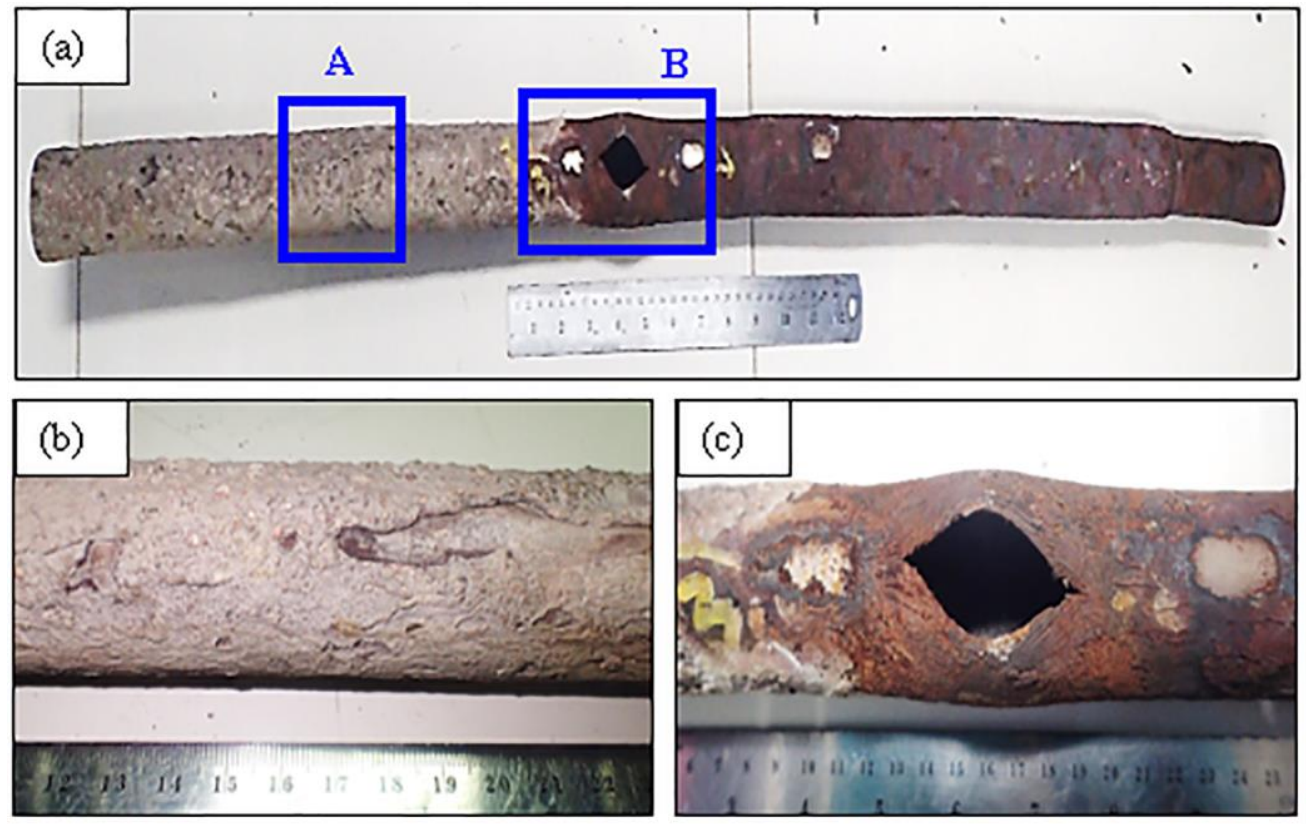

Figure 1. Photographs of the failed superheater tube: (a) The as-received failed superheater tube, (b) Area "A" indicating oxide layers formed on the external surface of the tube and (c) Area "B" showing wide-open burst with longitudinal direction

The as-received piece of the failed superheater tube was shown Figure 1(a). It is obvious that this tube was covered with thick oxide layers at area " $\mathrm{A}$ " and the fish-mouth opening of the failed tube was observed at area "B". Figure 1(b) shows the presence of the thick oxide layers in 
area "A". This thick oxide layers would be indicative of the excessive thermal oxidation, which had occurred during a long-term thermal exposure period. Figure 1(a) showed that the tube had failed with a wide-open burst with longitudinal direction as indicated in area "B". The close-up view of this failed area in Figure 1(c) clearly showed the thick-lip fish-mouth opening. Basically, thick-lipped opening in the failed area of the tube indicated that this failure was mainly related to the long-term overheating and eventually failed by stress rupture (Ahmad et al , 2012, Saha and Roy, 2017). In order to examine the surface conditions of the outer surface of the tube, the failed tube was sectioned and then investigated at area 1 and area 2 as exhibited in Figure 2(a).
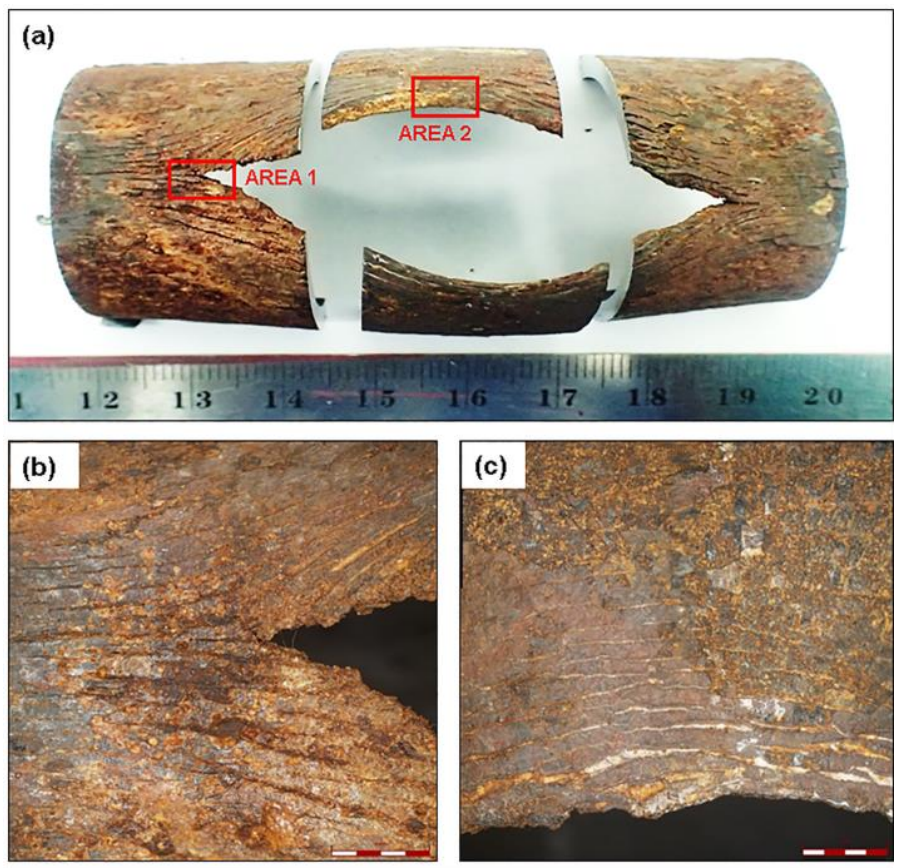

Figure 2. The external surface of the failed area: (a) The failed area covered with the oxide layers, (b) The oxide layers cracked along the tube-axis at area1 and (c) The oxide layers cracked along the tube-axis at area 2

Figure 2(a) showed the external surface of the failed area of the obtained tube. Obviously, the failed area was covered with the oxide layers, indicating the involvement of the excessive thermal oxidation. Evidently, these layers contained longitudinal cracks and the spallation of oxide layers was also found, as shown in Figure 2(b)-(c). Normally, long-term overheating can produce the thermal stressing and also promote the deformation of the tube (Sunandrioa, 2017). 
Hence, longitudinal cracks and the spallation of oxide layers in this failure can be contributed to the long-term overheating. In addition, the spallation of oxide layers can result in the wallthinning of the tube, which was subsequently resulted in the generation of excessive hoop stress acting on the tube (Haribhakti et al , 2018).
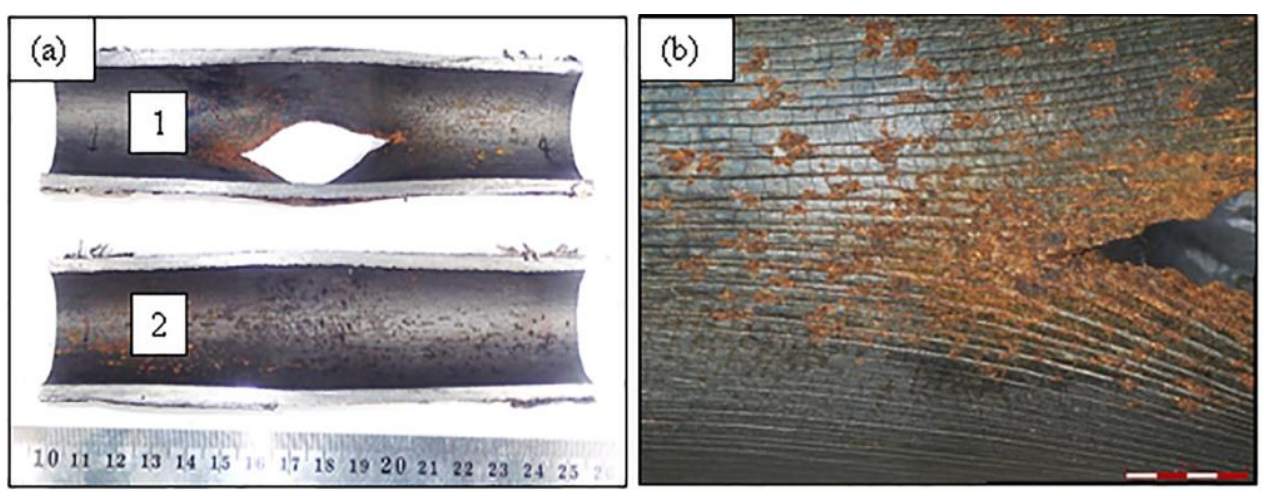

Figure 3. The internal surface of the failed tube: (a) tightly adherent scale on the internal surface and (b) longitudinal cracks of scale

Figure 3(a) showed the adherent scale on the internal surface of the tube. The presence of the longitudinal cracks of the scale was clearly seen in Figure 3(b). These cracks would be promoted by tube bulging as the excessive hoop stress was generated due to the thinning of the outer surface of the tube (Porta and Herro, 1991). Hence, this finding confirmed that the fracture of the failed tube was associated with long-term overheating and finally the stress rupture.

\section{Metallographic examination}

The cross-sectional sample for the metallurgical investigation was prepared from the failed area of the as-received failed tube and positions for this examination were given in Figure 4(a). As observed from Figure 4(b), the optical macrograph of the cross section at area 1 exhibited a gradual decrease in thickness in the failed tube at the edge of the fracture promoting the fishmouth opening. Figure 4(c) displayed elongated grains found near the fracture. These findings indicated the plastic deformation before fracture. 

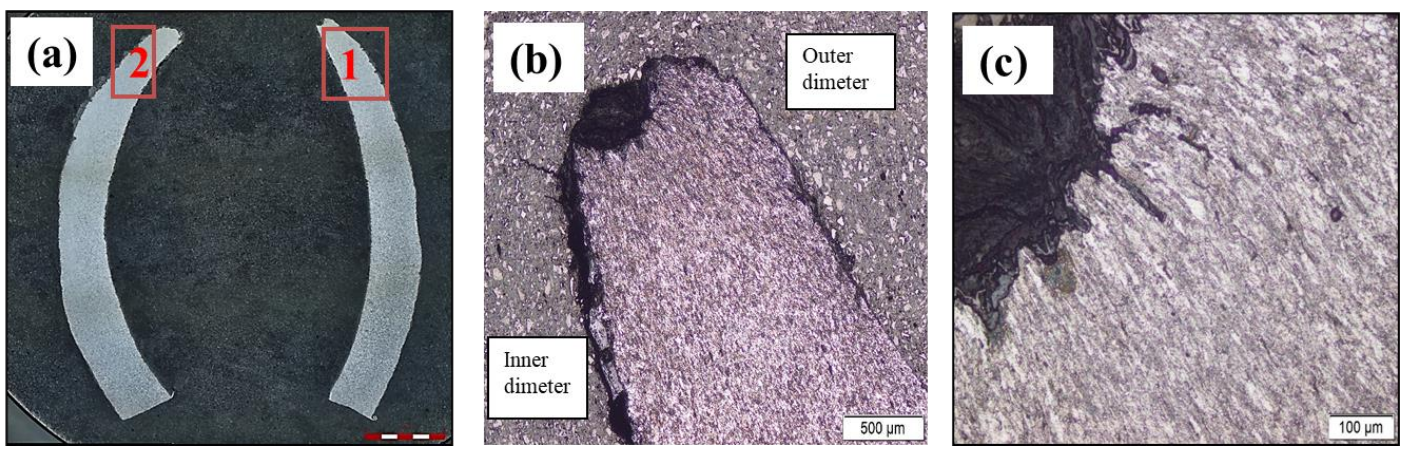

Figure 4. Metallographic analysis at Area 1: (a) macrophotograph of Cross-sectional sample, (b) optical micrograph showing a gradual decrease in thickness in the failed tube and (c) optical micrograph exhibiting elongated grains near the fracture

The microstructural examination was carried out on the area labelled 2 which was located in the mid-wall area of the sample and the results were given in Figure 5(a) and 5(b). Figure 5(a) showed the microstructure at a polished condition, displaying the presence of the random dispersion of nodular-shaped phase throughout the polished matrix. Microstructure of the etched sample prepared from the failed tube consisted of initial ferrite-pearlite structure with the formation of nodular-shaped phase, as clearly seen from Figure 5(b). A cluster of small nodularshaped particle was also observed in Figure 5(b). The presence of the small and large size of nodular-shaped particle displayed the microstructure alternation of the failed tube, recognized as "graphitization".
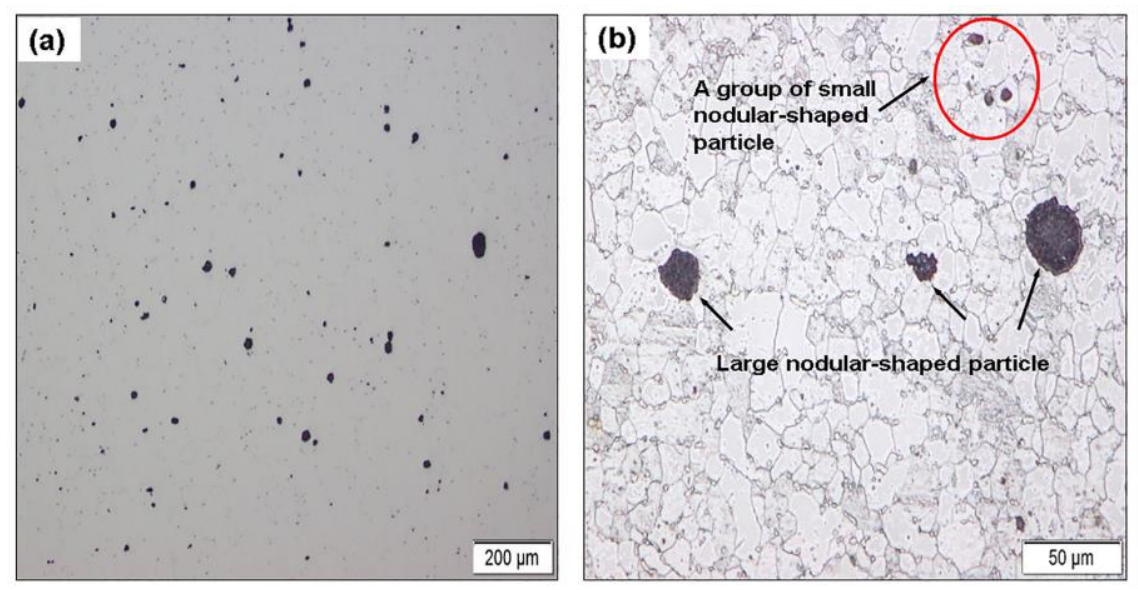
Figure 5. SEM micrographs at Area 2: (a) polished condition and (b) etched condition

Figure 6 presented the results from SEM micrographs of a nodular particle. Backscattering image in Figure 6(a) exhibited the nodular particle labelled "A", precipitated on the matrix labelled "B". Element map overlay result in Figure 6(b) clearly indicated the difference of the nodular morphology particle and the matrix. Figure 6(c) showed the accumulation of carbon was evidently observed in the nodular particle. In addition, the distribution of iron was obviously detected as shown in Figure 6(d). Therefore, the nodular particle A was composed of carbon, which should be the nodular-shaped graphite. In contrast, the matrix of the particle consisted of iron, indicating the presence of a ferrite structure. This finding confirmed the presence of the degraded microstructure and also suggested that the nodular-shaped particle observed in the micrograph analysis should be the formation of the nodular graphite and the presence of the small and large nodular-shaped particle should mean the initiation and growth of the nodular graphite, as clearly indicated in Figure 5(a)-(b). Therefore, these findings confirmed that the graphitization occurred and attributed to the microstructural degradation of the failed tube.
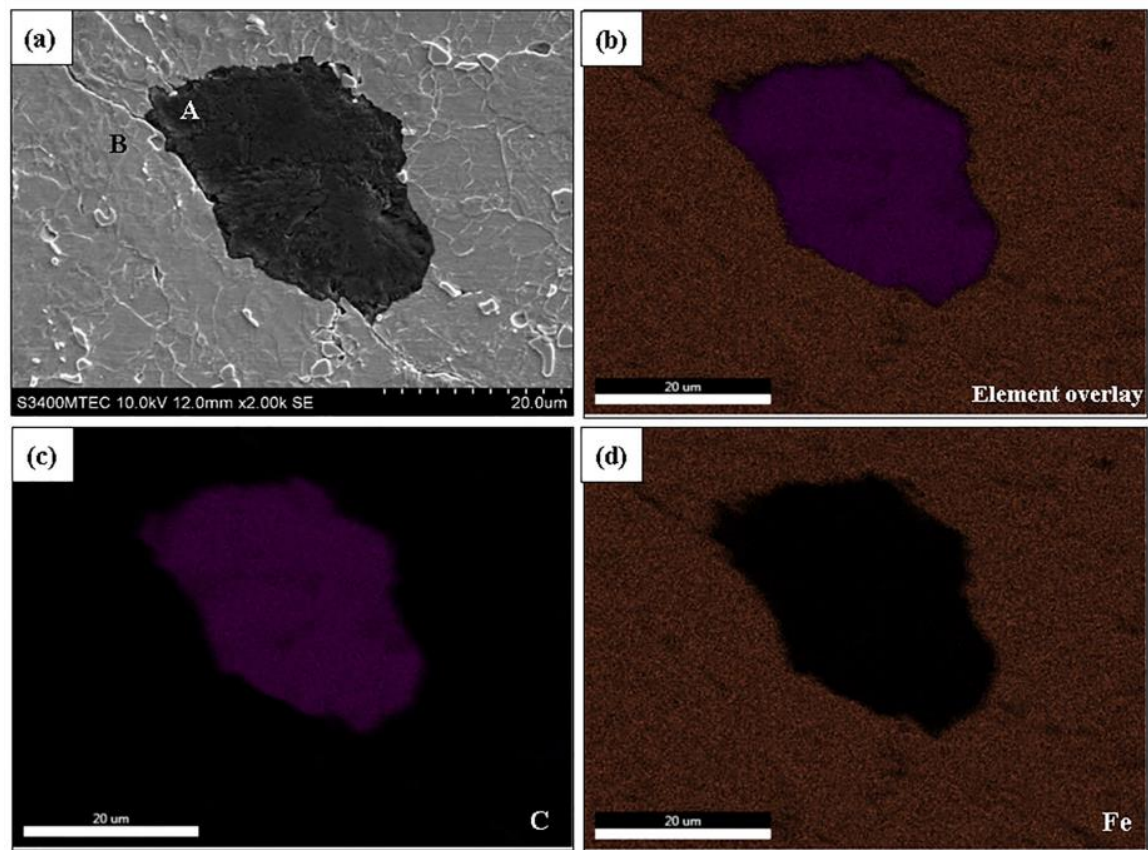

Figure 6. SEM micrographs together with EDS analysis of a nodular graphite: (a) backscattering image (b) element map overlay, (c) distribution of carbon and (d) distribution of iron. 
Pearlite is basically known as the main microstructure of the boiler tube and this phase is composed of the lamellar ferrite and cementite (Haribhakti et al ,2018). The presence of the lamellar cementite is responsible for the strength of pearlite, directly related to the load-bearing capacity of the steel tube. However, after prolonged local heating in the temperature range of 427 to $580{ }^{\circ} \mathrm{C}$, pearlite becomes unstable and the degradation of this phase can take place (Porta and Herro, 1991). Such extreme heat exposure promotes the transformation of cementite to free iron and nodular graphite, resulting in the degradation of mechanical properties and the pressure-bearing capacity of the heated tube.

\section{Chemical analysis}

The chemical analysis was caried out using the spectrometer. Its results were summarized and compared with the chemical composition required in the specification of SA 213 T22 and SA210

Grade C as shown in Table1 (ASME,2019).

Table 1. Chemical composition of the failed tube, SA213 T22 and SA210 Grade C

\begin{tabular}{|c|c|c|c|c|c|c|c|}
\hline \multirow[b]{2}{*}{ Element } & \multicolumn{7}{|c|}{ Composition (\%wt) } \\
\hline & C & Mn & $\mathbf{P}$ & $\mathbf{S}$ & $\mathbf{S i}$ & $\mathrm{Cr}$ & Mo \\
\hline SA213 T22 & $0.05-0.15$ & $0.30-0.60$ & 0.025 & 0.025 & 0.05 & $1.90-2.60$ & $0.87-1.13$ \\
\hline SA210 Gr. C & 0.350 & $0.290-1.060$ & 0.035 & 0.035 & 0.100 & - & \\
\hline Failed Tube & 0.305 & 0.446 & 0.008 & 0.021 & 0.207 & $<0.005$ & 0.026 \\
\hline
\end{tabular}

Chemical composition of the failed tube was different from that in SA213 T22, which is the designed material for the superheater tube in this biomass boiler. On the contrary, chemical composition of the failed tube corresponded to that of SA210 Grade C. Basically, SA210 Grade $\mathrm{C}$ is regarded as the carbon steel boiler tube without the addition of significant alloying elements (Prabu et al, 2014). Then, this kind of the boiler tube can undergo the degradation of its microstructure as exposed to the elevated temperature for a prolonged period of time, especially in the superheat zone of boilers. Technically, combined effects of the molybdenum and 
chromium added in carbon steels can retard the decomposition of pearlite and increase the thermal oxidation resistance during the thermal exposure (Bahrami et al, 2019). The degeneration of this phase undoubtedly leads to the degradation of mechanical properties and the integrity of the carbon steel boiler tubes. Instead, SA 213 T22 is known as one of low alloy steel boiler tubes, containing molybdenum and chromium as significant elements to improve the microstructural degradation resistance and the thermal oxidation resistance (Haribhakti et al , 2018 , Porta and Herro, 1991). So, in the severe operating conditions of the superheat zone, SA 213 T22 as the designed material should have better resistance to the degenerated microstructure and thermal oxidation when compared to the carbon steel boiler tube. Obviously, this severe environment of the superheater zone in this biomass boiler required the use of the higher-grade materials. Thus, carbon steels tube, SA 210 Grade C, utilized in the superheat zone of this boiler should be replaced by SA213 T22 to prevent the recurrence of the similar failure in this boiler.

\section{Hardness measurement}

The micro-hardness measurement was conducted on the failed area and undamaged area of the obtained tube. The measurement of the hardness was carried out for 7 points and the results were shown in Figure 7.

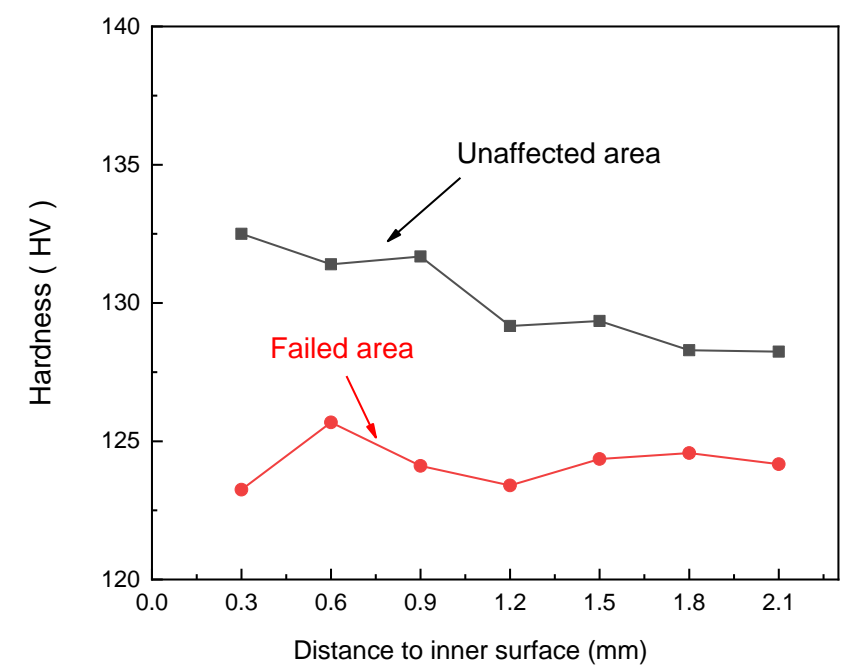

Figure 7. Micro-hardness results measured from the outer to inner surface.

The results exhibited that the hardness of the damaged area was significantly lower than that of 
the undamaged zone. The reduction of the hardness of the failed area normally reflected the degradation of the strength and integrity of the failed tube. Hence, this result obviously indicated the negative effect of the prolonged local heating, which consequently accelerated the decomposition of pearlite into ferrite and randomly distributed nodule graphite. Ferrite is regarded as the soft phase as compared to cementite. Therefore, the degradation the microstructure by the localized heating with the prolonged period of time attributed to the reduced hardness and degraded strength performance of the failed area of the damaged superheater tube.

\section{Degradation mechanism}

Based on the investigation results, the schematics diagram in illustrating the failure of the superheater tube can be given in Figure 9.

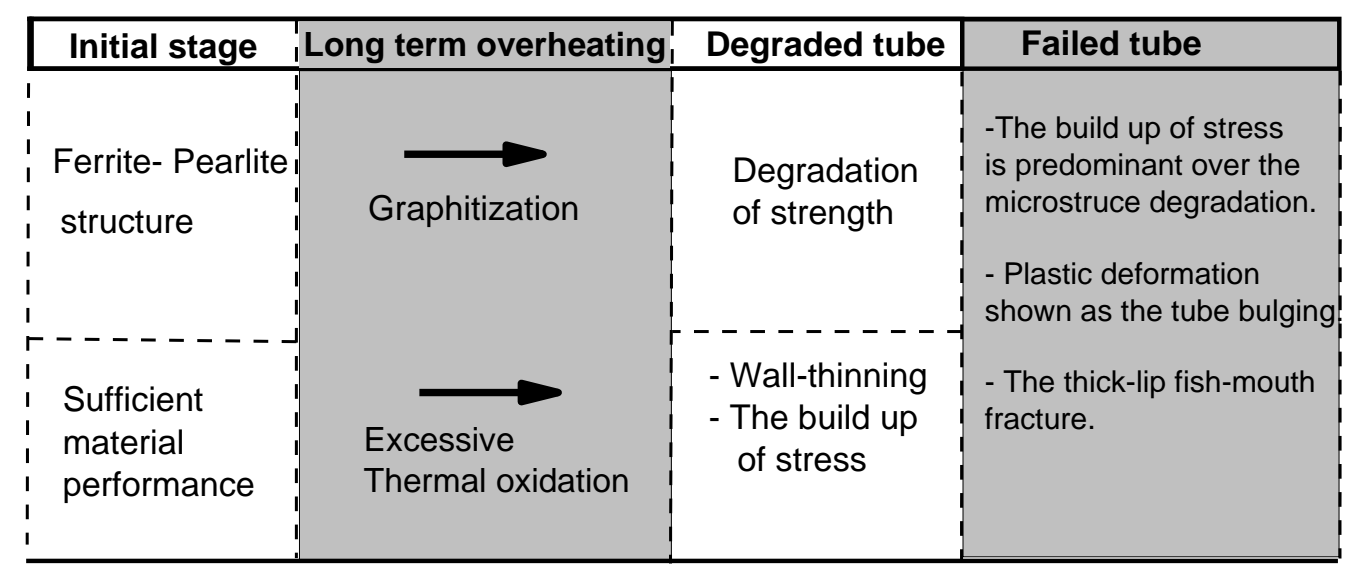

Figure 9. The schematic diagram in elucidating the failure mechanism of the incorrect material, SA 210 Grade $\mathrm{C}$ utilized in the biomass boiler.

SA 210 Grade C, the incorrect material, had been used in the superheat zone of the biomass boiler. In this zone, the exterior surface of the tube had to be subjected to the long-term thermal exposure and severe environments by the burning of the biomass fuels. Long-term localized heating resulted in the generation of the excessive thermal oxidation, leading to the formation of the thick oxide layers. The thermal stressing produced by the long-term overheating caused longitudinal cracks 
and spalled patches in oxide layers covering on the outer surface of the tube, resulting in the wall-thinning of the tube and subsequently increased hoop stress applying on the tube. The outer surface of the tube had experienced the localized heating for a prolonged period, resulting in the graphitization of the failed tube as shown in the following equation.

$$
\mathrm{Fe}_{3} \mathrm{C}=3 \mathrm{Fe}+\mathrm{C}
$$

Graphitization is related to the conversion of cementite $\left(\mathrm{Fe}_{3} \mathrm{C}\right)$ in pearlite to free iron $(\mathrm{Fe})$ and nodular graphite $(\mathrm{C})$, resulting in the mechanical performance degradation of the tube. As the tube continuously experiences long-term overheating, the wall-thinning process proceed, causing the excessive hoop stress in the failed area of the tube. At the same time, the graphitization process also takes place, resulting in the degraded material performance of the failed area of the tube.

When the build-up of the hoop stress is predominant over the microstructural degeneration effect, the tube becomes plastically deformed resulting in tube bulging and it finally failed by the stress rupture as shown in the thick-lip fish-mouth fracture at the failed area of the superheater tube. 


\section{CONCLUSION}

The failure of the failed superheater boiler tube which had been used in the biomass boiler for five years was already investigated. Results showed that this tube was mainly failed by longterm overheating, subsequently promoting the occurrence of the excessive thermal oxidation and graphitization on the tube. The severe thermal degradation resulted in the wall tube reduction and then increased the circumferential stress. Graphitization degenerated the microstructures of the tube, eventually reduced the materials performance of the tube. The combination of both effects from excessive thermal oxidation and graphitization was responsible for the failure of the superheater boiler tube. It was therefore recommended to replace the carbon steel tube in the failed section with the designed material, SA213 T22. Examination of material specifications for superheater regions prior to tube installations should be conducted to prevent the use of the improper material. The temperature monitoring and mapping in this section were also recommended.

\section{ACKNOWLEDGEMENTS}

The authors express their special gratitude to CORTECH Integrity and Expertise Co., Ltd for providing the necessary material and financial support for this investigation. 


\section{REFERENCES}

Movahedi-Rad, A., Plasseyed, S.S. \& Attarian, M. 2015. Failure analysis of superheater tube. Engineering Failure Analysis.48: 94-104.

Peeratatsuwan, C. \& Chowwanonthapunya, T. 2020. Study of Microstructure and Mechanical Property Degradation of SA210 A1 Boiler Tube. International Journal of Integrated Engineering.12(8) : 123-132.

Jenkins, B.M. 1989. Biomass Handbook, Gordon and Breach, New York.

Mckendry, P. 2002. Energy production from biomass (Part 1): Overview of biomass. Bioresource Technology.83: 37-46.

Popp, J., Kovacs, S., Olah, J., Diveki, Z. \& Balazs, E. 2021. Bioeconomy: Biomass and biomass-based energy supply and demand. New Biotechnology.60: 76-84.

Bahrami, A., Rafiaei, S.M. \& Mehr, M.Y. 2019.Root Cause Analysis of Failure in Superheater Tubes in a Power Plant Metallography. Microstructure, and Analysis.8:275-280.

Pramanick, A.K., Das, G., Das, S.K. \& Ghosh, M.2017.Failure investigation of super heater tubes of coal fired power plant. Case Studies in Engineering Failure Analysis .9:17-26.

Fryda, L., Sobrino, C., Cieplik, C. \& Van de Kamp, W.L. 2010. Study on ash deposition under oxyfuel combustion of coal/biomass blends. Fuel: the science and technology of fuel and energy.89: 1889-1902.

Chatterjee, U.K. 2012. Microstructure imprints in failure of power plant boiler tubes. Proceedings of the 15th International Conference on Applied Mechanics and Mechanical Engineering, Cairo, Egypt.

Liu, S.W., Wang, W.Z. \& Liu, C.J. 2017. Failure analysis of the boiler water-wall tube. Case Studies in Engineering Failure Analysis.9: 35-39.

Perez, I.U., da Silveira, T.L., da Silveira, T.F. \& Furtado, H.C. 2011. Graphitization in Low Alloy Steel Pressure Vessels and Piping. Journal of Failure Analysis and Prevention.11:3-9. 
Saha, A., Roy, H. \& Shukla, A.K. 2015. Failure Investigation of a Final Super Heater Tube in a 140 MW Thermal Power Plant. Journal of Failure Analysis and Prevention.15:184-189.

\section{Ahmad, J., Rahman, M.M. Zuhairi, M.H.A., Ramesh, S., Hassan, M.A. \& Purbolaksono, J.} 2012. High operating steam pressure and localized overheating of a primary superheater tube, Engineering Failure Analysis.26:344-348.

Saha, A. \& Roy, H. 2017. Failure Investigation of a Final Super Heater Tube in a 140 MW Thermal Power Plant. Case Studies in Engineering Failure Analysis.8: 57-60.

Xiaowei, L., Jing, N., Jianxun, Z., Anqing, F. \& Yaorong, F. 2014. Failure Analysis of Weld Cracking in a Thick-Walled 2.25Cr-1Mo Steel Pressure Vessel. Journal of Materials Engineering and Performance.23:1231-1239.

Chowwanonthapunya, T. \& Wiriyanon, R. 2015. Investigation of a cracked catalyst preparation vessel, Materials Performance.54: 64-67.

Sunandrioa, H., Suhartonoa, H.A. \& Prawotob, Y. 2017. Overheated pipe due to scale: Field failure investigation and finite element analysis. Case Studies in Engineering Failure Analysis.8: 36-38.

Haribhakti, P., Joshi, P.B. \& Kumar, R. 2018. Failure Investigation of Boiler tubes - A comprehensive approach, ASM International. USA.

Porta, R.D. \& Herro, H.M. 1991. The Nalco Guide to Boiler Failure Analysis, McGraw-Hill, New York,

ASME, 2019. Standard Specification for seamless Medium-Carbon Steel Boiler and Superheater Tubes, ASME SA-210/SA-210M.

ASME, 2019. Standard Specification for seamless Medium-Carbon Steel Boiler and Superheater Tubes, ASME SA-213/SA-213M.

Prabu, S.S., Jain, A., Gopinath, A., Arivazhagan, N., Ramkumar, K.D. \& Narayanan, S.2014. Investigation on the Mechanical Properties of SA 210 C Tubular Joints. Procedia Engineering.75:103-107. 